\title{
Assessing ecological vulnerability in western China based on Time-Integrated NDVI data
}

\author{
JIN Jia ${ }^{1,2}$, WANG Quan ${ }^{1,3^{*}}$ \\ ${ }^{1}$ Joint Research Center of Drylands, Xinjiang Institute of Ecology and Geography, Chinese Academy of Sciences, Urumqi \\ 830011, China; \\ ${ }^{2}$ University of Chinese Academy of Sciences, Beijing 100049, China; \\ ${ }^{3}$ Faculty of Agriculture, Shizuoka University, Shizuoka 422-8529, Japan
}

\begin{abstract}
Arid and semi-arid areas are the most vulnerable regions to climate change. Clear understanding of the effects of climate change on ecosystems in arid and semi-arid regions and the ecosystem vulnerability is important for ecosystem management under the background of climate change. In this study, we conducted a vulnerability assessment on various ecosystems from 1982 to 2013 in western China with large areas of arid and semi-arid lands based on the Time-Integrated Normalized Difference Vegetation Index (TINDVI) data and climate data. The results indicated that grasslands were the most vulnerable ecosystem to climate change in western China, especially for those in Tibetan Plateau. Croplands in oases were not vulnerable to climate change compared to rain-fed croplands in semi-arid regions (e.g. Gansu and Inner Mongolia), which was attributed to the well-developed drip irrigation technology in oases. Desert and Gobi ecosystems were slightly vulnerable to climate change during the past several decades. The assessment results, as revealed in this study, can provide a reference for taking appropriate actions to protect the ecosystems in western China.
\end{abstract}

Keywords: vulnerability; sensitivity; adaptability; climate change; Time-Integrated Normalized Difference Vegetation Index (TINDVI); western China

Citation: JIN Jia, WANG Quan. 2016. Assessing ecological vulnerability in western China based on Time-Integrated NDVI data. Journal of Arid Land, 8(4): 533-545. doi: 10.1007/s40333-016-0048-1

Global climate change has received worldwide attention over recent decades (Fang et al., 2013). There is now a scientific consensus that the climate is changing and the changing climate has a significant impact on different natural and managed ecosystems (He et al., 2013). These ecosystems also play important roles in regulating global and regional climate systems through feedback mechanisms (Fang et al., 2013). Arid and semi-arid areas are highly vulnerable with less available water and dramatic increase in water consumption ( $\mathrm{Li}$ et al., 2007), and are enlisted as the most vulnerable regions affected by climate change (Parry et al, 2007). Under the background of climate change, ecosystems in arid and semi-arid areas are expected to undergo significant perturbation (Lioubimtseva, 2004) and are identified as the most responsive ecosystems with considerable variability and uncertainty (Zheng and Wang, 2013).

In China, land degradation/desertification, coming to terms with ecological vulnerability, occurs widely and is identified as one of the most severe ecological issues threatening and constraining regional sustainable development, especially in western China (Xu and Zhang, 2014; Wang et al., 2015). Almost all arid, semi-arid and sub-humid areas in China have suffered from

\footnotetext{
*Corresponding author: WANG Quan (E-mail: aqwang@ipc.shizuoka.ac.jp)

Received 2015-07-31; revised 2016-01-04; accepted 2016-03-13

(C) Xinjiang Institute of Ecology and Geography, Chinese Academy of Sciences, Science Press and Springer-Verlag Berlin Heidelberg 2016
} 
serious soil erosion for a long time (Zhao et al., 2013; König et al., 2014; Li et al., 2014; Cao et al., 2015; Zhao et al., 2015), which influences soil aggregate stability, a synthetic parameter of the soil ecosystem with the potential to serve as a sensitive indicator of soil degradation (Montanarella and Tóth, 1986; Cerdà, 1998a, b, 2000). Aeolian desertification has rapidly developed in the past 50 years in northern China, affecting nearly $0.17 \times 10^{9}$ people, causing the direct and indirect economic loss of about $54 \times 10^{9}$ Chinese Yuan $\left(6.75 \times 10^{9}\right.$ U.S. dollars) per year, and contributing significantly to dust loading in the atmosphere (Wang et al., 2008). The total aeolian desertified area in China was $0.14 \times 10^{6} \mathrm{~km}^{2}$ in 1955 , and it increased to $0.18 \times 10^{6} \mathrm{~km}^{2}$ in 1975 and $0.33 \times 10^{6} \mathrm{~km}^{2}$ in 1987, and reached to $0.39 \times 10^{6} \mathrm{~km}^{2}$ in 2000 (Wang et al., 2004a). On average, the area of aeolian desertified land in China was developed at an increasing rate of 1,560 $\mathrm{km}^{2} / \mathrm{a}$ from 1955 to $1975,2,100 \mathrm{~km}^{2} / \mathrm{a}$ from 1976 to 1987 and 3,600 km²/a from 1988 to 2000 (Wang et al., 2004b). In aeolian desertified regions, clear understanding of the effects of climate change on ecosystems as well as the ecosystem vulnerability are critical to regional sustainable management. Since arid and semi-arid areas cover more than half of the total land area in western China, and still expand with an increasingly worsening degree (Li et al., 2004; Liu and Diamond, 2005; Fu and Ma, 2008), there is an urgent need to assess the ecological vulnerability in western China (Geng et al., 2014).

Water resource is one of the major constraints in western China. Drought has significant impacts on agricultural, ecological and economic development (Geng et al., 2014), and its intensity can be assessed (Tsakiris and Vangelis, 2005). Drought indices, such as Palmer Drought Index (PDI), Standardized Precipitation Index (SPI), Reconnaissance Drought Index (RDI) and Standardized Precipitation Evapotranspiration Index (SPEI), which can be easily applied to quantitatively assess drought intensity (Agnew, 2000; Wilhite et al., 2000; Mishra and Singh, 2010), have been proposed for drought assessment during the past several decades (Guttman, 1998; Heim, 2002; Keyantash and Dracup, 2002; Ji and Peters, 2003; Li et al., 2004; Ghulam et al., 2007; Tsakiris et al., 2007; Vicente-Serrano et al., 2010; Shahabfar et al., 2012; Choi et al., 2013; Wu et al., 2013). They are important parameters for drought monitoring and assessment since they simplify the complex interrelationships between climate parameters, such as precipitation, solar radiation, air temperature, wind velocity, air humidity, albedo and so on (Heim, 2000; Tsakiris and Vangelis, 2005).

Studies about the impacts of climate change on natural ecosystems in China have been conducted previously, including vulnerability assessment (Zhao and Wu, 2014). However, most of the previous studies on the assessment were based on driving inputs with lower spatial and temporal resolutions (Zhao et al., 2009). Wu et al. (2007) developed a vulnerability assessment method to assess the ecosystem vulnerability in China, in which net primary production (NPP), length of growing season and aridity index were used as the assessment indicators.

Ecosystems are continuously changing, leading to increasing difficulty in their monitoring. Remote sensing (RS) technique, which provides a good way to understand the condition of ground ecosystem at large scales or for long terms, is considered as a good choice to overcome the barrier of ecosystem monitoring. The main advantages of RS data are their applicability to large area analysis and their high temporal resolutions to trace the vegetation dynamics.

A number of studies have validated and confirmed that the Normalized Difference Vegetation Index (NDVI) is directly related to the photosynthetic capacity and hence energy absorption of plant canopies (Sellers et al., 1992; Myneni and Hall, 1995). Furthermore, its time-integrated alternatives, i.e. the Time-Integrated Normalized Difference Vegetation Index (TINDVI), were used to evaluate the ecosystem conditions, such as photosynthetic potential, gross primary productivity (GPP) and biomass (Wang et al., 2005; Wylie et al., 2005). Kaushalya et al. (2014) pointed out that variations in NDVI could reflect the impact of climate change on vegetation growth and vigor. They used NDVI as an indicator to study agricultural vulnerability in India, and identified the agricultural vulnerability at a district level. Their study was based on the change trends in climate factor, which was represented by the SPI. However, they only applied the coefficient of variation of the maximum NDVI to assess the agricultural vulnerability. Therefore, their approach may not clearly indicate the integrative effects of climate factors on agricultural vulnerability. Alternatively, in this study, we 
used the annual fluctuation of TINDVI and variability of climate change as indicated by drought index to examine the ecological vulnerability in western China. The main objectives of the study were: (1) to understand the change trend of drought in western China over recent decades; and (2) to assess the ecological vulnerability of ecosystems to climate change in western China.

\section{Study area and methods}

\subsection{Study area}

The study area is the western China and covers a total area of about $5.2 \times 10^{6} \mathrm{~km}^{2}$, including all areas of Xinjiang, Gansu, Inner Mongolia, Qinghai and Tibet, the western parts of Heilongjiang, Jilin and Liaoning, and the northern parts of Hebei, Shanxi, Shannxi and Ningxia (Fig. 1). The region is droughty with an annual precipitation of $<500 \mathrm{~mm}(\mathrm{Xu}, 1991)$. In general, the eastern part of the region is wetter than the western part. The elevation of this region ranges from $-155 \mathrm{~m}$ (below sea level) to 8,614 m. Different ecosystems, such as cropland, forest, shrubland, grassland and desert are distributed in this region, and their spatial distribution is shown in Fig. 1. Croplands are mainly distributed in southeastern part of this region as well as in oases of western part. Forests cover the northeastern and southwestern parts of this region, and grasslands are widely found in northeastern and southwestern parts of this region. Moreover, desert and Gobi are mainly distributed in northwestern part of the region. Recently, rapid population growth and migration to the marginal arid and semi-arid areas have exacerbated the land degradation and water depletion in this region (Huo et al., 2013).

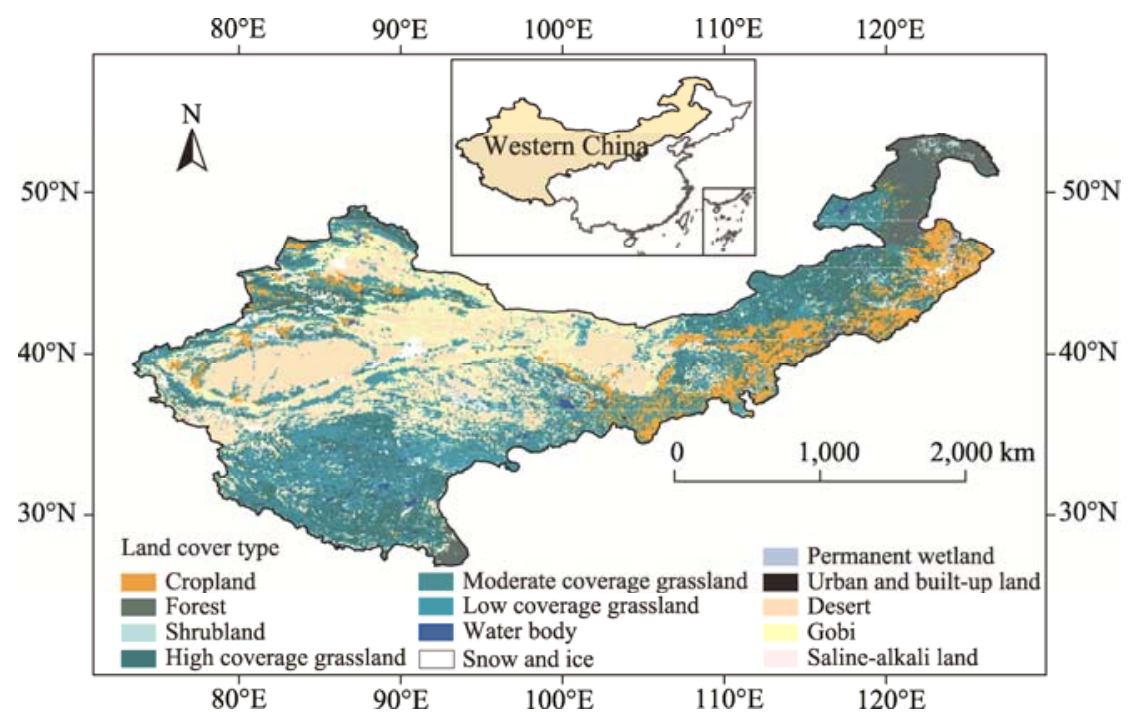

Fig. 1 Spatial distribution of land cover types in western China. The dataset was provided by the Environmental and Ecological Science Data Center for West China (http://westdc.westgis.ac.cn).

\subsection{Climate data}

In this study, the daily meteorological data (including mean temperature $\left({ }^{\circ} \mathrm{C}\right)$, precipitation $(\mathrm{mm})$, mean relative humidity (\%), mean wind speed $(\mathrm{m} / \mathrm{s})$ and sunshine duration (h)) of 228 meteorological stations in our study region (Fig. 2) from 1960-2014 were collected from China Meteorological Data Sharing Service System of China Meteorological Administration (http://data.cma.cn/). Other variables such as reference evapotranspiration and drought index were then calculated based on these daily meteorological data.

The spatial distributions of precipitation and TINDVI in western China are shown in Fig. 2. Fewer meteorological stations were observed with an average annual precipitation of $>300 \mathrm{~mm}$. Furthermore, most areas of the region had very low TINDVI values $(<30)$, although the maximum TINDVI value of 165 was noted within the region. 


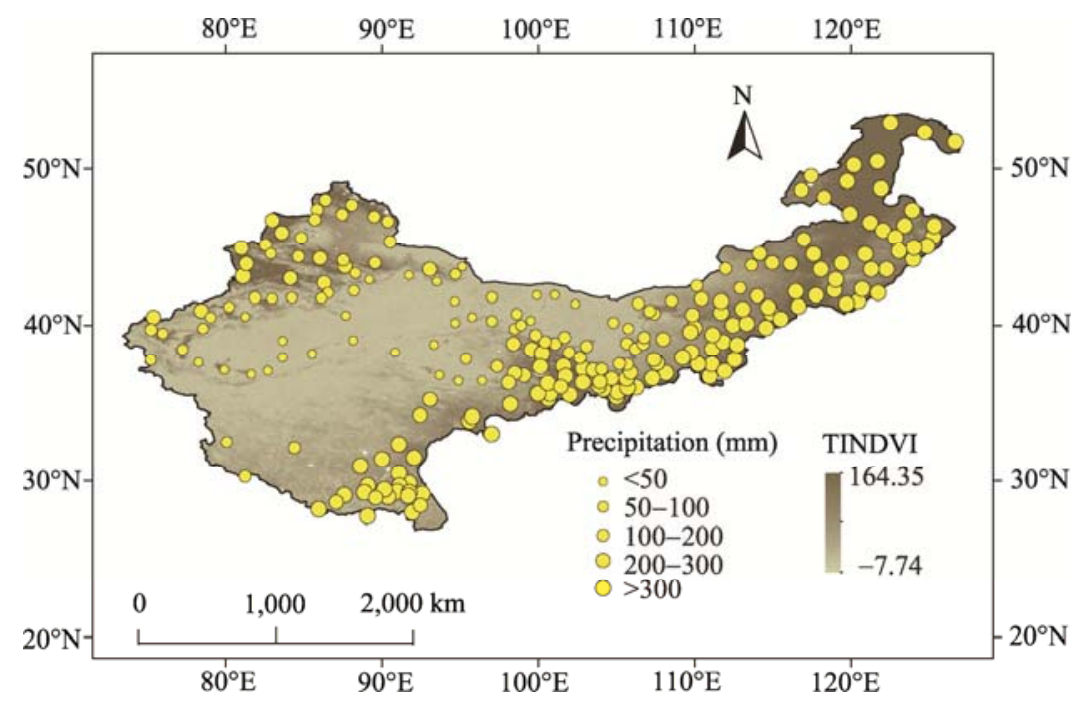

Fig. 2 Spatial distributions of annual precipitation (1960-2014) and TINDVI (Time-Integral Normalized Difference Vegetation Index; 1982-2013) in western China. Precipitation data were from the observed average annual precipitation values of 228 meteorological stations in western China with different sizes.

Reference evapotranspiration ( $\left.\mathrm{ET}_{0}\right)$ was calculated by the FAO Penman-Monteith equation with the collected meteorological data (Allen et al., 1998).

$$
\mathrm{ET}_{0}=\frac{0.408 \times \Delta \times\left(R_{n}-G\right)+\gamma \times \frac{900}{T+273} \times U_{2} \times\left(e_{s}-e_{a}\right)}{\Delta+\gamma \times\left(1+0.34 U_{2}\right)} .
$$

Where, $\Delta$ is the slope vapour pressure curve $\left(\mathrm{kPa} /{ }^{\circ} \mathrm{C}\right) ; R_{n}$ is the net radiation $\left(\mathrm{MJ} /\left(\mathrm{m}^{2} \cdot \mathrm{d}\right)\right)$, which can be estimated based on the recorded sunshine duration and the calibration equation by Chen et al. (2006); $G$ is the soil heat flux density $\left(\mathrm{MJ} /\left(\mathrm{m}^{2} \cdot \mathrm{d}\right)\right)$, approximating 0 at the daily scale; $\gamma$ is the psychrometric constant $\left(\mathrm{kPa} /{ }^{\circ} \mathrm{C}\right)$, approximating $66 \mathrm{kPa} /{ }^{\circ} \mathrm{C} ; T$ is the mean daily air temperature at 2-m height $\left({ }^{\circ} \mathrm{C}\right) ; U_{2}$ is the wind speed at $2-\mathrm{m}$ height $(\mathrm{m} / \mathrm{s})$; and $e_{s}-e_{a}$ is the vapour pressure deficit (VPD; kPa).

Drought is the main constraint factor inhibiting agricultural, ecological and economic development in western China. In arid and semi-arid regions, evapotranspiration is closely related to plant transpiration (Li et al., 2014), so we defined drought index (DI) as Eq. 2 (Tsakiris and Vangelis, 2005).

$$
\mathrm{DI}=\frac{\mathrm{PREC}}{\mathrm{ET}_{0}}
$$

Where, PREC is the precipitation ( $\mathrm{mm})$ and $\mathrm{ET}_{0}$ is the reference evapotranspiration (mm).

\subsection{NDVI time series and TINDVI calculation}

At present, there are several available long-term NDVI databases, e.g. NOAA-AVHRR NDVI (spatial resolution of $8 \mathrm{~km}$ ), SPOT4-VEGETATION NDVI (spatial resolution of $1 \mathrm{~km}$ ) and MODIS-NDVI\&EVI (spatial resolution of $1 \mathrm{~km}$ or $250 \mathrm{~m}$ ). Among them, NOAA-AVHRR NDVI data are available in a consistently processed database at an 8-km re-sampling grid covering the entire planet. Compared to other datasets, NOAA-AVHRR NDVI database has the longest time series. The GIMMS3g (Global Inventory Modeling and Mapping Studies $3^{\text {rd }}$ generation) NDVI dataset is available at http://ecocast.arc.nasa.gov/data/pub/gimms/.

In this study, the NOAA-AVHRR GIMMS3g NDVI products from 1982-2013 were used to evaluate and trace the conditions of ecosystems in western China. This downloaded NDVI products had a temporal resolution of $15 \mathrm{~d}$ and a spatial resolution of $8 \mathrm{~km}$, and was used for analyzing NDVI matrix derivations.

We first reconstructed the continuous annual NDVI time series for each pixel within the study 
area based on a mean-value iteration (MVI) filter method proposed by Ma and Veroustraete (2006). After the MVI filter, a double logistic function, which was demonstrated to be particularly well suited for phonological monitoring from RS data, was fitted on the corrected AVHRR time series for producing continuous NDVI curves (Beck et al., 2006; Fisher et al., 2006; Busetto et al., 2010). The double logistic function was as follows:

$$
\operatorname{NDVI}(t)=\mathrm{NDVI}_{w}+\left(\mathrm{NDVI}_{\max }-\mathrm{NDVI}_{w}\right) \times\left(\frac{1}{1+\mathrm{e}^{-m S \times(t-S)}}+\frac{1}{1+\mathrm{e}^{m A \times(t-A)}}-1\right) .
$$

Where, $\operatorname{NDVI}(t)$ is the NDVI of the pixel at day of year (DOY) $t$; $\mathrm{NDVI}_{w}$ is the winter NDVI value; $\mathrm{NDVI}_{\max }$ is the maximum NDVI during the year; $S$ is the DOY of maximum slope of the curve in spring; $A$ is the DOY of minimum slope of the curve in autumn; $m S$ and $m A$ are the slopes of the curve at DOYs $S$ and $A$, respectively.

The value of TINDVI was then calculated from the reconstructed continuous annual NDVI time series. Previous studies have revealed that TINDVI had a linear relationship with dry/green biomass, NPP, GPP and photosynthetic potential (Wang et al., 2005; Nakayama and Shankman, 2013).

\subsection{Vulnerability assessment}

A precise index for the assessment of vulnerability should express the sensibility and adaptability of ecosystems to climate change or extreme events. Sensitivity is the degree to which a system is affected, either adversely or beneficially, by climate-related stimuli (Parry et al., 2007). The effect may be direct (e.g. a change in crop yield in response to a change in the mean, range or variability of temperature) or indirect (e.g. damages caused by an increase in the frequency of coastal flooding due to sea level rise). In this study, sensibility $(S)$ was defined as Eq. 4.

$$
S=\frac{C V_{\mathrm{TINDVI}}}{C V_{\mathrm{DI}}}
$$

The coefficient of variation of TINDVI ( $\left.C V_{\text {TINDVI }}\right)$ at the inter-annual scale can indicate the variability of ecosystem, and the coefficient of variation of DI $\left(C V_{\mathrm{DI}}\right)$ shows the severity of climate change. A higher sensibility value suggests that the ecosystem is more sensitive to climate change during the study period and vice versa.

Ecosystem adaptability is the capacity of ecosystems to maintain their functions and services under the external disturbance from climate change or other anthropogenic impacts (Parry et al., 2007). In this study, ecosystem adaptability $(A)$ was defined as Eq. 5. A higher value indicates that the ecosystem has a lower ability to adapt the climate change and vice versa.

$$
A=\frac{\sum_{i=1}^{n}\left|\frac{\mathrm{TINDVI}_{i}-\mathrm{TINDVI}_{\text {mean }}}{\mathrm{DI}_{i}-\mathrm{DI}_{\text {mean }}}\right|}{n} .
$$

Where, TINDVI $_{i}$ is the TINDVI value of the pixel in year $i$; TINDVI mean $_{\text {in }}$ is the mean TINDVI value of the pixel over the study period; $\mathrm{DI}_{i}$ is the $\mathrm{DI}$ value of the pixel in year $i$; $\mathrm{DI}_{\text {mean }}$ is the mean DI value of the pixel over the study period.

Finally, according to the definition of vulnerability proposed by IPCC (Parry et al., 2007), we assessed the ecosystem vulnerability ( $V$ ) as: $V=S+A$. $S$ and $A$ were normalized to restrict them into the same range.

\section{Results}

\subsection{Spatial-temporal patterns of drought index in western China}

The change trend of drought index during 1982-2014 obtained from 228 stations in the study region is shown in Fig. 3. Apparent fluctuations of drought index values were observed in this region. The lowest value occurred in 1997 with a departure of -0.04 to the baseline, suggesting that 1997 was an extremely dry year during the study period.

The study region can generally be separated into 4 sub-regions based on the geographic 
features and topographic similarity (Fig. 4). Region A mainly covers Xinjiang, which is an arid and semi-arid region with large-scale desert ecosystems; region B includes both territories of Gansu and Ningxia with large areas of Gobi; region C mainly covers Inner Mongolia with large-scale grasslands; and region D is located on the Tibetan Plateau. Figure 4 also presented the spatial distribution of drought index in western China. The drought index showed great variations at regional scales. It can be easily recognized that region $\mathrm{A}$ is the most arid area with the minimum drought index of 0.03 , and the northeastern part of region $\mathrm{C}$ is the relatively wet area with the maximum value of 0.78. In general, the southeastern part are wetter than the northwestern part.

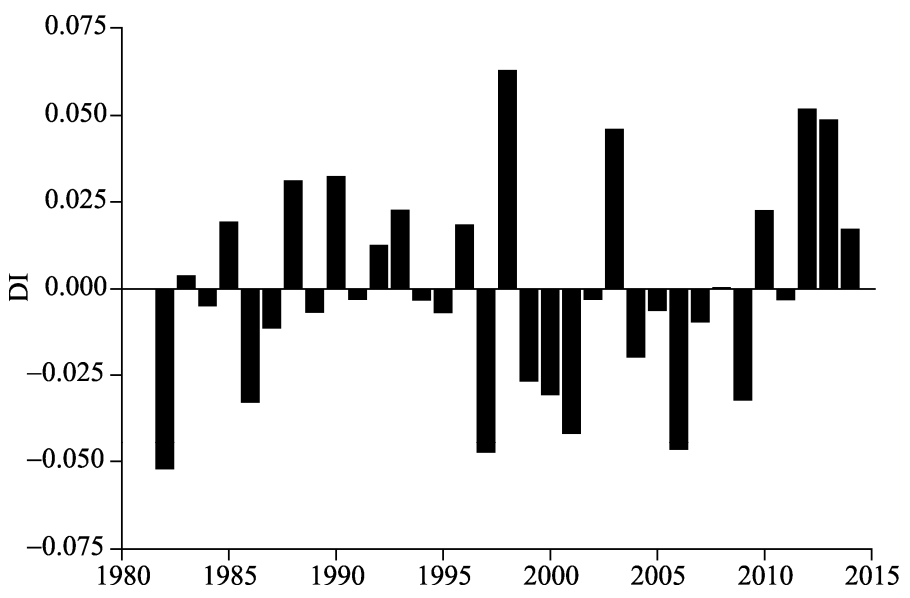

Fig. 3 Variations of drought index (DI) in western China from 1982-2014

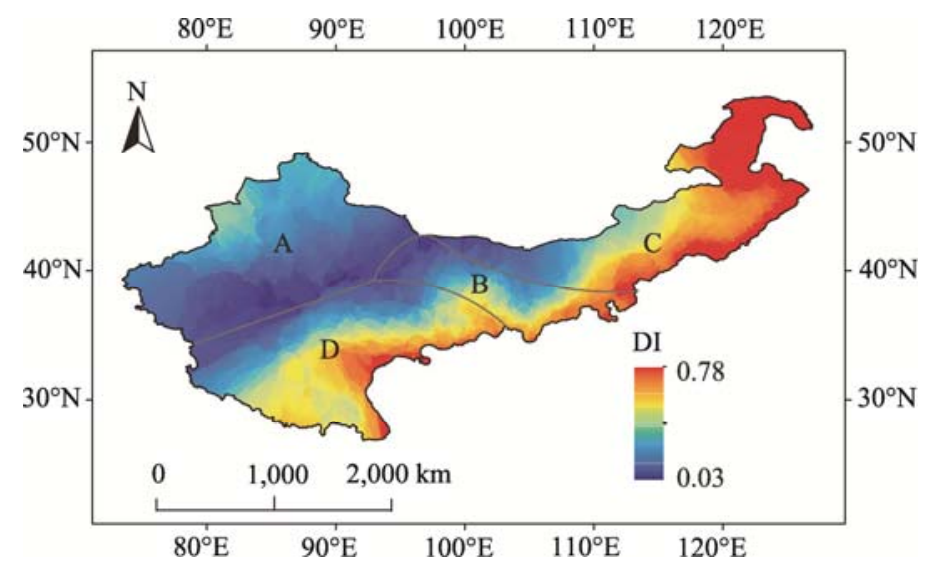

Fig. 4 Spatial distribution of drought index (DI) in western China. A, B, C and D are 4 sub-regions based on the geographic features and topographic similarity.

\subsection{Sensitivity and adaptability of ecosystems in western China}

Figure 5 showed the sensitivity and adaptability of ecosystems in western China to climate change during 1982-2013. Results revealed that the Tibetan Plateau (marked as D on the map) and Hexi Corridor (marked as B on the map) were the regions with high sensitivity to climate change in the past several decades, followed by Hetao Plain located in southwestern part of region $\mathrm{C}$ with a moderate sensitivity (Fig. 5a). Meanwhile, Tarim Basin and Junggar Basin in region A as well as Horqin Grassland in southeastern part of region C, were slightly sensitive to climate change.

For ecosystem adaptability, almost all areas in western China showed a low adaptability to climate change during the study period except Tarim Basin and Junggar Basin which maintained steady condition with low TINDVI values (Fig. 5b). The grasslands in northeastern part of Inner Mongolia had the lowest adaptability to climate change. 

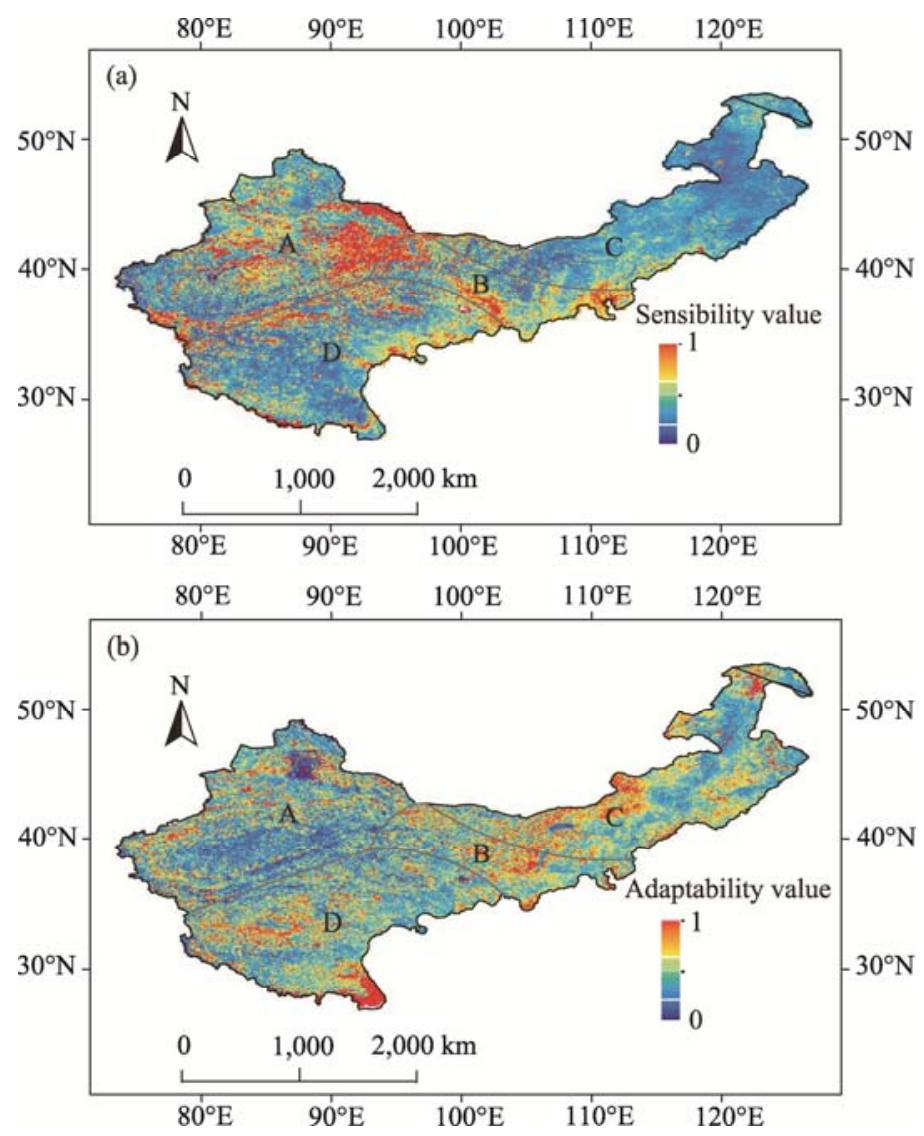

Fig. 5 Spatial patterns of sensibility (a) and adaptability (b) of ecosystems to climate change during 1982-2013

Different types of ecosystems retrieved from the WESTDC Land Cover Products 1.0 (spatial resolution of $1 \mathrm{~km}$ ) (Ran et al., 2010) also showed varying sensibility and adaptability to climate change (Fig. 6). Cropland and forest ecosystems were moderately sensitive to climate change, and showed lower adaptability. Desert, Gobi and saline-alkali land ecosystems were not sensitive but quite adaptable to climate change.

On the one hand, low coverage grassland ecosystem had a higher adaptability to climate change than high and moderate coverage grassland ecosystems. On the other hand, low and moderate coverage grassland ecosystems were more sensitive to climate change than high coverage grassland ecosystem.

\subsection{Vulnerability assessment in western China}

The spatial distribution of vulnerability of ecosystems to climate change during 1982-2013 is shown in Fig. 7. Ecosystems located in northern part of the region were characterized by relatively high vulnerability with significant differences in ecological vulnerability at the regional level. Overall, nearly $10 \%$ of the entire region had high vulnerability values $(>0.5)$.

Ecosystems in western part of Hetao Plain and southwestern part of Tibetan Plateau were extremely vulnerable, indicating that climate change was likely to have a serious impact on natural ecosystems in these regions.

Forest ecosystems in northeastern part of Inner Mongolia showed extreme vulnerability to climate change, while Horqin Grassland in eastern part of Inner Mongolia was slightly vulnerable to climate change (Fig. 8). Most grassland ecosystems in Inner Mongolia were moderately vulnerable to climate change, which represented the degradation trend of grasslands in the past several decades.

Croplands had moderate vulnerability to climate change, and the vulnerability value of rain-fed 

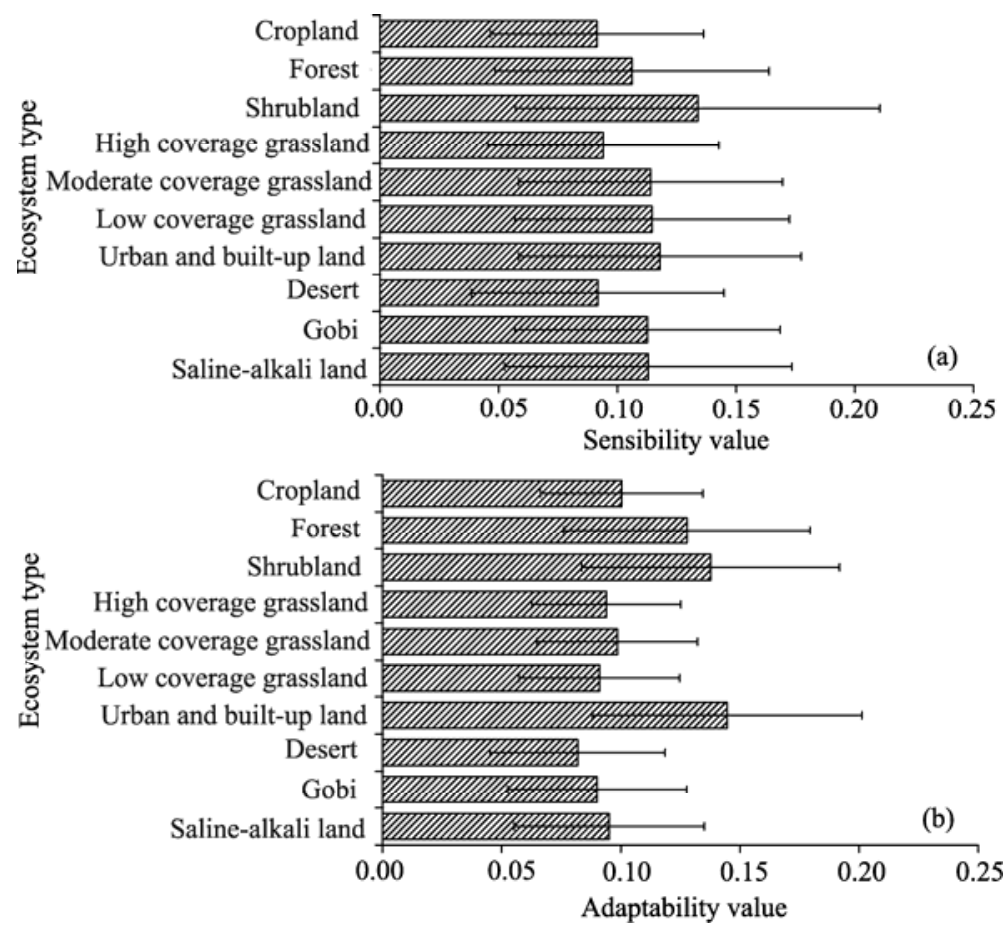

Fig. 6 Sensibility (a) and adaptability (b) of different ecosystems to climate change during 1982-2013. Bars mean standard errors.

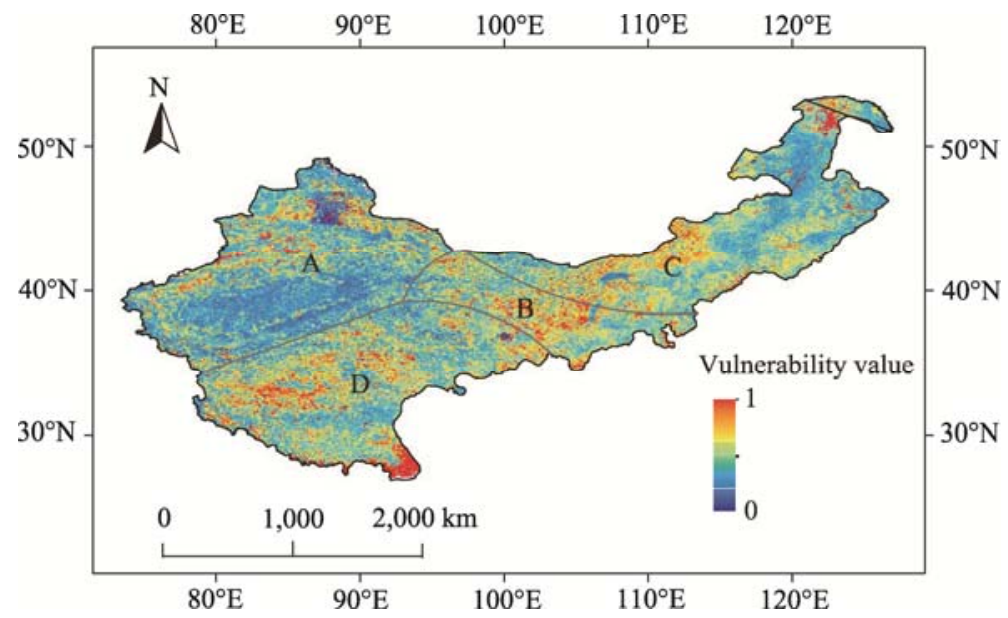

Fig. 7 Spatial distribution of vulnerability of ecosystems to climate change during 1982-2013

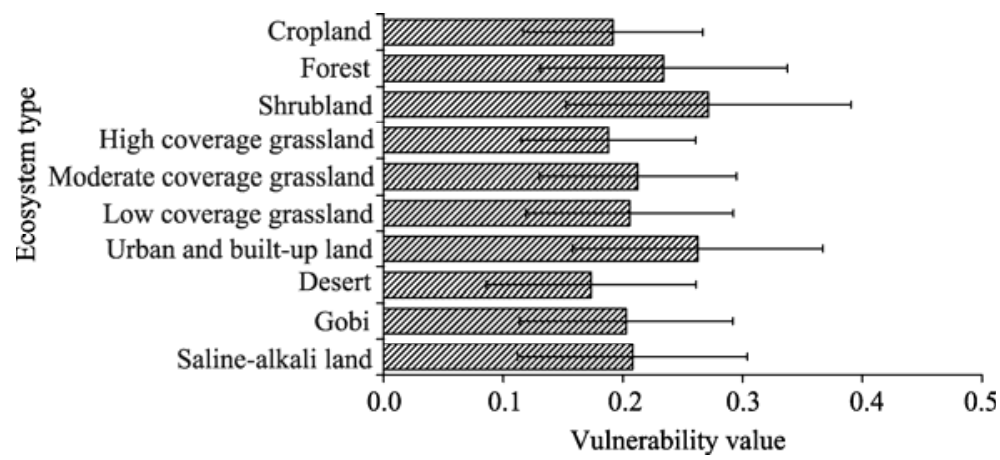

Fig. 8 Vulnerability of different ecosystems to climate change during 1982-2013. Bars mean standard errors. 
croplands in Loess Plateau was 0.8, which was much higher than those of croplands in Inner Mongolia (about 0.3) and oases of Xinjiang (about 0.1). Moreover, most desert ecosystems in western China seemed to be in steady condition, and were slightly vulnerable to climate change during the past several decades.

\section{Discussion}

Spatial patterns of ecosystem vulnerability in this study were similar to the results proposed by Wu et al. (2007) and Zhao et al. (2014). Compared to previous studies, the TINDVI data, which can represent the semi-real condition of ecosystems instead of simulated ecosystem NPP or $\mathrm{CO}_{2}$ flux, were used in our assessment system.

For ecosystem vulnerability assessment, NDVI and TINDVI data have advantages in terms of long-time resolution and large spatial scale compared to NPP or other ecological indices. Furthermore, TINDVI can reflect the condition of ecosystems in certain time of the growing season with an annual time resolution, while NDVI only presents the composited condition of ecosystems at 15-day intervals.

In this study, drought index was applied to describe climate change. Drought index simplify the complex interrelationships between climate and climate-related parameters and thus is an important indicator for drought monitoring and assessment. Compared with other climatic parameters, dryness illustrates the direct impacts of climate change on ecosystem functions, especially for arid and semi-arid areas in western China where drought is the predominant climate phenomenon (Qian and Zhu, 2001).

Different ecosystems in western China respond differently to climate change (Fig. 8). Shrublands and grasslands were the two most vulnerable ecosystems in this region. By contrast, desert and Gobi ecosystems were quite stable and only slightly vulnerable to climate change. Croplands was moderately vulnerable to climate change in this region.

Based on the current results, we found that cropland and forest ecosystems were moderately sensitive to climate change and showed slightly adaptability to climate change. Furthermore, desert, Gobi and saline-alkali land ecosystems were not sensitive but quite adaptable to climate change. Low coverage grassland ecosystem exhibited a higher adaptability and lower sensitivity to climate change than the other grassland ecosystems.

Large spatial variability existed even for the same type of ecosystem within the region. In this study, we used the spatial distributions of cropland and grassland vulnerability to illustrate this (Fig. 9). Cropland and grassland are the two main ecosystem types that have attracted great interest in recent decades.

There are two main types of cropland in this region: cropland with irrigation system in oases, and rain-fed cropland in semi-arid regions. Assessment results clearly indicated that the rain-fed cropland was the most vulnerable ecosystem with the high vulnerability value of approximately 0.8 . As a comparison, the oasis cropland had the lowest vulnerability value since the cropland water is irrigated by drip irrigation technology in this ecosystem, so it was not vulnerability to climate change (Wu, 2010).

The grasslands in Tibetan Plateau were extremely vulnerable to climate change since they suffered from harsh climates in the past several decades (Zhang et al., 2000; Li et al., 2006; Ding et al., 2007; Wang et al., 2007; Zhong et al., 2010). However, grasslands in middle part of Inner Mongolia showed a moderate vulnerability to climate change. This may be attributed to the conservation efforts for preventing grassland degradation in the past several decades (Jiang et al., 2006; Li et al., 2013; Mu et al., 2013). Horqin Grassland in eastern part of Inner Mongolia was slightly vulnerable to climate change due to several years of degeneration since the 1980s (Tang et al., 2014), where restoration efforts were absent (Akiyama and Kawamura, 2007). Furthermore, grasslands in Xinjiang also showed a low vulnerability to climate change as a result of decreased effect of human activities. 


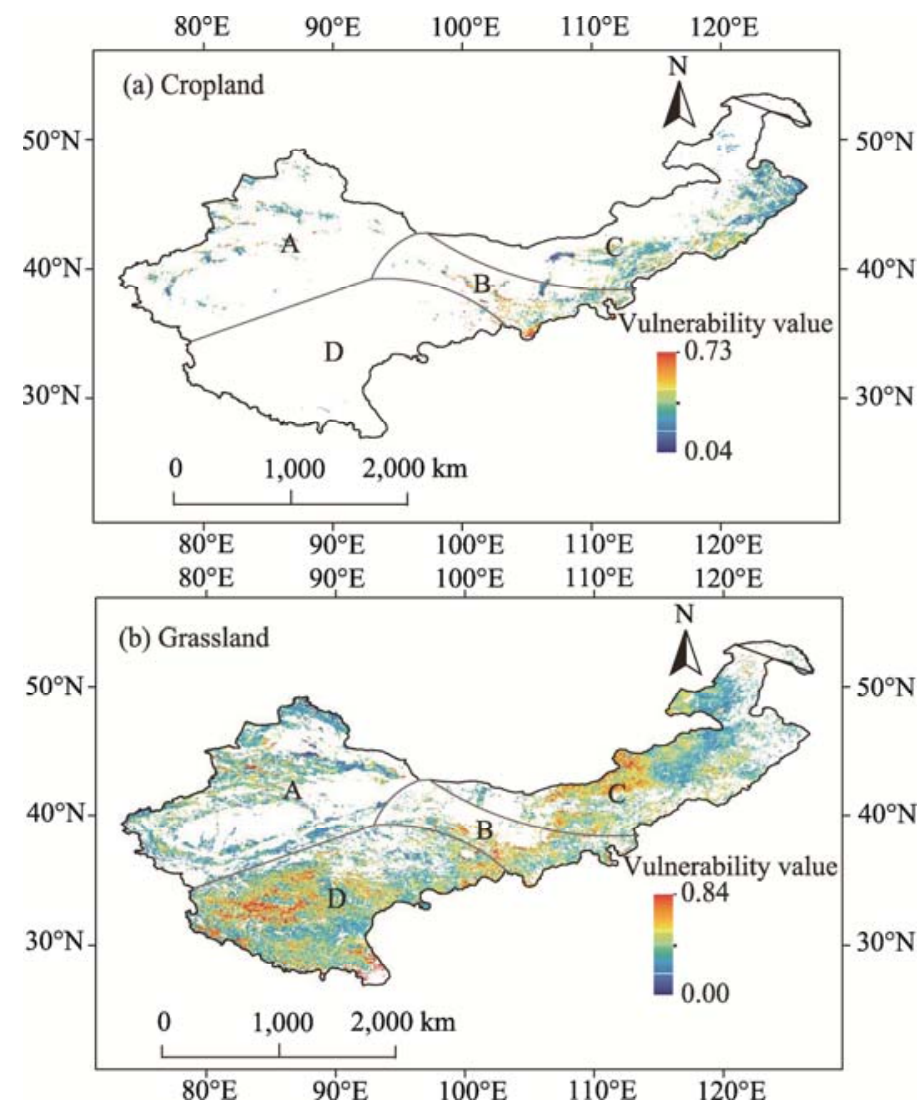

Fig. 9 Spatial distributions of vulnerability of (a) cropland and (b) grassland ecosystems to climate change during 1982-2013

\section{Conclusions}

In this study, we carried out a vulnerability assessment of ecosystems in western China from 1982 to 2013 based on TINDVI data and climate data. The results indicated that grasslands in this region were the most vulnerable ecosystem to climate change, especially those in Tibetan Plateau. Croplands in oases were not as vulnerable to climate change as rain-fed croplands in semi-arid areas due to the well-developed drip irrigation technology. Both desert and Gobi ecosystems showed slightly vulnerability to climate change during the past several decades. At the spatial scales, the central and southwestern parts of western China showed high ecosystem vulnerability to climate change, while ecosystems in eastern part of Inner Mongolia, southeastern and northern parts of Xinjiang show low vulnerability to climate change. Even though the TINDVI data, which can present the semi-real conditions of ecosystems, was used in our vulnerability assessment, species transition or extinction and human activities were not investigated in this study, and should be considered in future studies.

\section{Acknowledgments}

This study was supported by the National Basic Research Program of China (2012CB956204) and the National Natural Science Foundation of China (41101249).

\section{References}

Agnew C T. 2000. Using the SPI to identify drought. Drought Network News, 12(1): 6-12.

Akiyama T, Kawamura K. 2007. Grassland degradation in China: Methods of monitoring, management and restoration. Grassland Science, 53(1): 1-17. 
Allen R G, Pereira L S, Raes D, et al. 1998. Crop evapotranspiration-Guidelines for computing crop water requirements. FAO Irrigation and Drainage Paper 56, 1-15.

Beck P S A, Atzberger C, Høgda K A, et al. 2006. Improved monitoring of vegetation dynamics at very high latitudes: A new method using MODIS NDVI. Remote Sensing of Environment, 100(3): 321-334.

Busetto L, Colombo R, Migliavacca M, et al. 2010. Remote sensing of larch phenological cycle and analysis of relationships with climate in the Alpine region. Global Change Biology, 16(9): 2504-2517.

Cao L X, Zhang K, Dai H L, et al. 2015. Modeling interrill erosion on unpaved roads in the loess plateau of China. Land Degradation \& Development, 26(8): 825-832.

Cerdà A. 1998a. Effect of climate on surface flow along a climatological gradient in Israel: a field rainfall simulation approach. Journal of Arid Environments, 38(2): 145-159.

Cerdà A. 1998b. Relationships between climate and soil hydrological and erosional characteristics along climatic gradients in Mediterranean limestone areas. Geomorphology, 25(1-2): 123-134.

Cerdà A. 2000. Aggregate stability against water forces under different climates on agriculture land and scrubland in southern Bolivia. Soil and Tillage Research, 57(3): 159-166.

Chen R S, Lu S H, Kang E S, et al. 2006. Estimating daily global radiation using two types of revised models in China. Energy Conversion and Management, 47(7-8): 865-878.

Choi M, Jacobs J M, Anderson M C, et al. 2013. Evaluation of drought indices via remotely sensed data with hydrological variables. Journal of Hydrology, 476: 265-273.

Ding M J, Zhang Y L, Liu L S, et al. 2007. The relationship between NDVI and precipitation on the Tibetan Plateau. Journal of Geographical Sciences, 17(3): 259-268.

Fang S F, Yan J W, Che M L, et al. 2013. Climate change and the ecological responses in Xinjiang, China: Model simulations and data analyses. Quaternary International, 311: 108-116.

Fisher J I, Mustard J F, Vadeboncoeur M A. 2006. Green leaf phenology at Landsat resolution: Scaling from the field to the satellite. Remote Sensing of Environment, 100(2): 265-279.

Fu C B, Ma Z G. 2008. Global change and regional aridification. Chinese Journal of Atmospheric Sciences, 32(4): 752-760. (in Chinese)

Geng Q L, Wu P T, Zhang Q F, et al. 2014. Dry/wet climate zoning and delimitation of arid areas of Northwest China based on a data-driven fashion. Journal of Arid Land, 6(3): 287-299.

Ghulam A, Qin Q M, Zhan Z M. 2007. Designing of the perpendicular drought index. Environmental Geology, 52(6): 1045-1052.

Guttman N B. 1998. Comparing the palmer drought index and the standardized precipitation index. Journal of the American Water Resources Association, 34(1): 113-121.

He D, Liu Y L, Pan Z H, et al. 2013. Climate change and its effect on reference crop evapotranspiration in central and western Inner Mongolia during 1961-2009. Frontiers of Earth Science, 7(4): 417-428.

Heim Jr R R. 2000. Drought indices: a review. In: Wilhite D A. Drought: A Global Assessment (Vol. 1). London, New York: Routledge, 159-167.

Heim Jr R R. 2002. A review of twentieth-century drought indices used in the United States. Bulletin of the American Meteorological Society, 83(8): 1149-1165.

Huo Z L, Dai X Q, Feng S Y, et al. 2013. Effect of climate change on reference evapotranspiration and aridity index in arid region of China. Journal of Hydrology, 492: 24-34.

Ji L, Peters A J. 2003. Assessing vegetation response to drought in the northern Great Plains using vegetation and drought indices. Remote Sensing of Environment, 87(1): 85-98.

Jiang G M, Han X G, Wu J G. 2006. Restoration and management of the Inner Mongolia grassland require a sustainable strategy. AMBIO, 35(5): 269-270.

Kaushalya R, Kumar V P, Shubhasmita S. 2014. Assessing agricultural vulnerability in India using NDVI data products. The International Archives of Photogrammetry, Remote Sensing and Spatial Information Sciences, XL-8: 39-46.

Keyantash J, Dracup J A. 2002. The quantification of drought: An evaluation of drought indices. Bulletin of the American Meteorological Society, 83(8): 1167-1180.

König H J, Zhen L, Helming K, et al. 2014. Assessing the impact of the sloping land conversion programme on rural sustainability in Guyuan, western China. Land Degradation \& Development, 25(4): 385-396.

Li Q Y, Fang H Y, Sun L Y, et al. 2014. Using the ${ }^{137} \mathrm{C}_{\mathrm{S}}$ technique to study the effect of soil redistribution on soil organic carbon and total nitrogen stocks in an agricultural catchment of northeast China. Land Degradation \& Development, 25(4): 350-359. 
Li R, Tsunekawa A, Tsubo M. 2014. Index-based assessment of agricultural drought in a semi-arid region of Inner Mongolia, China. Journal of Arid Land, 6(1): 3-15.

Li S G, Asanuma J, Kotani A, et al. 2007. Evapotranspiration from a Mongolian steppe under grazing and its environmental constraints. Journal of Hydrology, 333(1): 133-143.

Li S L, Yu F H, Werger M J A, et al. 2013. Understanding the effects of a new grazing policy: the impact of seasonal grazing on shrub demography in the Inner Mongolian steppe. Journal of Applied Ecology, 50(6): 1377-1386.

Li X R, Jia X H, Dong G R. 2006. Influence of desertification on vegetation pattern variations in the cold semi-arid grasslands of Qinghai-Tibet Plateau, North-west China. Journal of Arid Environments, 64(3): 505-522.

Li X Z, Liu X D, Ma Z G. 2004. Analysis on the drought characteristics in the main arid regions in the world since recent hundred-odd years. Arid Zone Research, 21(2): 97-103. (in Chinese)

Lioubimtseva E. 2004. Climate change in arid environments: revisiting the past to understand the future. Progress in Physical Geography, 28(4): 502-530.

Liu J G, Diamond J. 2005. China’s environment in a globalizing world. Nature, 435(7046): 1179-1186.

Ma M G, Veroustraete F. 2006. Reconstructing pathfinder AVHRR land NDVI time-series data for the Northwest of China. Advances in Space Research, 37(4): 835-840.

Mishra A K, Singh V P. 2010. A review of drought concepts. Journal of Hydrology, 391(1-2): 202-216.

Montanarella L, Tóth G. 2008. Desertification in Europe. New York: Springer Science+Business Media, 110-125.

Mu S J, Zhou S X, Chen Y Z, et al. 2013. Assessing the impact of restoration-induced land conversion and management alternatives on net primary productivity in Inner Mongolian grassland, China. Global and Planetary Change, 108: $29-41$.

Myneni R B, Hall F G. 1995. The interpretation of spectral vegetation indexes. IEEE Transactions on Geoscience and Remote Sensing, 33(2): 481-486.

Nakayama T, Shankman D. 2013. Evaluation of uneven water resource and relation between anthropogenic water withdrawal and ecosystem degradation in Changjiang and Yellow River basins. Hydrological Processes, 27(23): 3350-3362.

Parry M L, Canziani O F, Palutikof J P. 2007. Climate Change 2007: Impacts, Adaptation and Vulnerability: Working Group II to the Fourth Assessment Report of the Intergovernmental Panel on Climate Change. Cambridge: Cambridge University Press.

Qian W H, Zhu Y F. 2001. Climate change in China from 1880 to 1998 and its impact on the environmental condition. Climatic Change, 50(4): 419-444.

Ran Y H, Li X, Lu L. 2010. Evaluation of four remote sensing based land cover products over China. International Journal of Remote Sensing, 31(2): 391-401.

Sellers P J, Berry J A, Collatz G J, et al. 1992. Canopy reflectance, photosynthesis, and transpiration. III. A reanalysis using improved leaf models and a new canopy integration scheme. Remote Sensing of Environment, 42(3): 187-216.

Shahabfar A, Ghulam A, Eitzinger J. 2012. Drought monitoring in Iran using the perpendicular drought indices. International Journal of Applied Earth Observation and Geoinformation, 18: 119-127.

Tang Y, Jiang D M, Lü X T. 2014. Effects of exclosure management on elm (Ulmus pumila) recruitment in Horqin sandy land, Northeastern China. Arid Land Research and Management, 28(1): 109-117.

Tsakiris G, Vangelis H. 2005. Establishing a drought index incorporating evapotranspiration. European Water, 9(10): 3-11.

Tsakiris G, Pangalou D, Vangelis H. 2007. Regional drought assessment based on the Reconnaissance Drought Index (RDI). Water Resources Management, 21(5): 821-833.

Vicente-Serrano S M, Beguería S, López-Moreno J I. 2010. A multiscalar drought index sensitive to global warming: The standardized precipitation evapotranspiration index. Journal of Climate, 23(7): 1696-1718.

Wang G X, Wang Y B, Li Y S, et al. 2007. Influences of alpine ecosystem responses to climatic change on soil properties on the Qinghai-Tibet Plateau, China. CATENA, 70(3): 506-514.

Wang Q, Ni J, Tenhunen J. 2005. Application of a geographically-weighted regression analysis to estimate net primary production of Chinese forest ecosystems. Global Ecology and Biogeography, 14(4): 379-393.

Wang T, Wu W, Xue X, et al. 2004a. Study of spatial distribution of sandy desertification in North China in recent 10 years. Science in China Series D: Earth Sciences, 47(1): 78-88.

Wang T, Wu W, Xue X, et al. 2004b. Spatial-temporal changes of sandy desertified land during last 5 decades in northern China. Acta Geographica Sinica, 59(2): 203-212. (in Chinese)

Wang T, Xue X, Luo Y Q, et al. 2008. Human causes of aeolian desertification in Northern China. Sciences in Cold and Arid Regions, (1): 0001-0013.

Wang T, Xue X, Zhou L, et al. 2015. Combating aeolian desertification in Northern China. Land Degradation \& Development, 26(2): 118-132. 
Wilhite D A, Hayes M J, Svoboda M D. 2000. Drought monitoring and assessment: Status and trends in the United States. In: Vogt J V, Somma F. Drought and Drought Mitigation in Europe. Netherlands: Springer, 149-160.

Wu J J, Zhou L, Liu M, et al. 2013. Establishing and assessing the Integrated Surface Drought Index (ISDI) for agricultural drought monitoring in mid-eastern China. International Journal of Applied Earth Observation and Geoinformation, 23: 397-410.

Wu P T. 2010. The modern water-saving agricultural technology: Progress and focus. African Journal of Biotechnology, 9(37): 6017-6026.

Wu S H, Dai E F, Huang M, et al. 2007. Ecosystem vulnerability of China under B2 climate scenario in the $21^{\text {st }}$ century. Chinese Sciences Bulletin, 52(7): 811-817.

Wylie B K, Fosnight E A, Smart A J, et al. 2005. Quantifying regional range condition for erosion and carbon modeling, In: AGU Fall Meeting Abstracts. AGU, Washington, DC, 1: B43B-0281.

Xu E Q, Zhang H Q. 2014. Characterization and interaction of driving factors in karst rocky desertification: a case study from Changshun, China. Solid Earth, 5(2): 1329-1340.

Xu S Y. 1991. Classification of arid climate in China and its characteristics. Scientia Geographica Sinica, 11(1): 1-9. (in Chinese)

Zhang D F, Fengquan L, Jianmin B. 2000. Eco-environmental effects of the Qinghai-Tibet Plateau uplift during the Quaternary in China. Environmental Geology, 39(12): 1352-1358.

Zhao D S, Wu S H. 2014. Vulnerability of natural ecosystem in China under regional climate scenarios: An analysis based on eco-geographical regions. Journal of Geographical Sciences, 24(2): 237-248.

Zhao G J, Mu X, Wen Z M, et al. 2013. Soil Erosion, conservation, and eco-environment changes in the Loess Plateau of China. Land Degradation \& Development, 24(5): 499-510.

Zhao J F, Yan X D, Jia G S. 2009. Changes in carbon budget of Northeast China forest ecosystems under future climatic scenario. Chinese Journal of Ecology, 28(5): 781-787. (in Chinese)

Zhao X, Wu P, Gao X, et al. 2015. Soil quality indicators in relation to land use and topography in a small catchment on the Loess Plateau of China. Land Degradation \& Development, 26(1): 54-61.

Zheng C L, Wang Q. 2013. Spatiotemporal variations of reference evapotranspiration in recent five decades in the arid land of Northwestern China. Hydrological Processes, 28(25): 6124-6134.

Zhong L, Ma Y M, Salama M S, et al. 2010. Assessment of vegetation dynamics and their response to variations in precipitation and temperature in the Tibetan Plateau. Climatic Change, 103(3-4): 519-535. 